\title{
The Influence of Licorice Root (Glycyrrhiza glabra) on Sex Reversal in Guppy Poecilia reticulata
}

\author{
Funda TURAN *1 \\ ${ }^{1}$ Iskenderun Technical University, Faculty of Marine Science and Technology, Department of Aquaculture, \\ Turkey
}

Received: 06 May 2017 - Revised: 18 August 2017 - Accepted: 16 September 2017

\begin{abstract}
The roots and rhizomes of licorice (Glycyrrhiza) species have long been used worldwide as a herbal medicine and natural sweetener. Licorice is commonly present in menopausal botanical supplements in the United States. The estrogenic activities of different licorice species are variable and likely depend on the type and amounts of bioactive compounds. This study examined the effects of Licorice root extract on sex reversal in guppy, Poecilia reticulata. Newly born guppy fry $(0.014 \pm 0.001$ mean weight), were randomly distributed into $30 \mathrm{~L}$ aquaria at a density of 80 fish per aquarium and subjected to a sex-reversal treatment by immersion application of licorise root extract for 30 days. The licorise root extract was incorporated into the aquarium water as follows: 0 (control), 0.25 and $0.5 \mathrm{~g} / \mathrm{L}$ licorice root extract. Each of the treatment group was randomly assigned to triplicate groups of fish. The treatment was repeated twice (in the beginning and half way through the experiment) during 30 days. At the end of experiment, the highest feminization $(88 \%)$ was observed at $0.5 \mathrm{~g} \backslash \mathrm{L}$ licorise root extract group. Morphological and histological examinations of the gonads in all groups revealed no intersex fish. Histological examination of fish treated with licorise root revealed no damage to the testes or ovaries. This study demonstrated successful sex reversal with treatment of licorise root on new-born progenies of $P$. reticulate.
\end{abstract}

Keywords: Guppy, Poecilia reticulata, Licorice Root, Glycyrrhiza glabra, Sex reversal

\section{INTRODUCTION}

In last decade, the total world fishery production decreased slightly and the human consumption for aquatic product increased. The reduction in capture fisheries was partly compensated for the fast growth of aquaculture industry and this sector is the world's fastest growing sector of agricultural [1]. With the increasing intensification and commercialization of aquaculture production, fish culture is globally expanding into new directions, intensifying and diversifying for enhanced disease resistance, feed efficiency, and growth performance of cultured organisms. Therefore, several growth promoters and hormones have been tested for enhancing feed conversion efficiency and for increasing fish culture productivity [2]. However, the recent consumer demand for farmed fish has increasingly stressed quality and safety, and the absence of pollutants, antibiotics and carcinogens. Thus, along with growth performance, the fish rearing strategy needs to focus on food hygiene. This global demand for safe food has prompted the search for natural alternative growth promoters to be used in aquatic feeds. There has been heightened research in developing new dietary supplementation strategies in which

*Corresponding Author E-mail: funda.turan@iste.edu.tr 
various health and growth promoting compounds as probiotics, prebiotics, synbiotics, phytobiotics and other functional dietary supplements have been evaluated [3].

Phytooestrogens are estrogenic compounds found in $>300$ species of plants that can mimic oestrogen activity [4]. Phytooestrogens of current medical interest are the isoflavones, which are widely used as oestrogen replacement in human post-menstrual treatment and as a breast cancer preventive treatment [5]. A conspicuous feature of the chemical structure of phytooestrogen is the presence of a phenolic ring that, with few exceptions, is prerequisite for binding to the oestrogen receptor (ER). It was initially believed that phytooestrogens action would be predominantly hormonal, but as this field of study has expanded over the past decade, it has become apparent from the diversity of properties of isoflavones that no single action can explain many of the in vivo and in vitro effects in the same organism $[5,6]$. The oestrogenic potency of these compounds on fish has been documented [7-11].

The roots and rhizomes of licorice (Glycyrrhiza) species have long been used worldwide as a herbal medicine. The active component of licorice, glycyrrhizic acid, is hydrolyzed in vivo to glycyrrhetinic acid, which is responsible for most of its pharmacological properties. In ancient Chinese medicine and during Roman times, licorice was also recommended to cure sterility of women $[12,13]$. Theophrastus and Pliny also reported an efficacy of licorice in reducing hunger and thirst $[13,14]$. In addition, licorice extract has some estrogen-like, antiviral, and antioxidant properties [12]. The estrogenic activities of different licorice species are variable and likely depend on the type and amounts of bioactive compounds.

Licorice root (Glycyrrhiza glabra) is also able to affect androgen metabolism in human [13]. Various studies have demonstrated that licorice blocks the activity of 3 - $\beta$-hydroxysteroid dehydrogenase (3HSD), 17- hydroxysteroid dehydrogenase (17HSD) and 17-20 lyase [13, 15] and stimulates the activity of aromatase [16-18]. All these enzymes are involved in the synthesis and/or metabolism of androgens and estrogens. A possible compensatory mechanism is the binding of glycyrrhetinic acid to sex binding globulin, thus increasing free testosterone and estradiol values [19].

Considering these aspects, the present study was focused to evaluate the efficacy of licorise root as potent alternatives for induction of sex reversal in fish. The live-bearing guppy, Poecilia reticulata is a popular freshwater species among aquarium hobbyists. In this study, guppies have used as a model fish for investigating the influence of Licorice root (Glycyrrhiza glabra) on sex reversal in fish.

\section{MATERIAL and METHODS}

Newly born guppy fry $(0.014 \pm 0.001$ mean weight), were randomly distributed into 30 $\mathrm{L}$ aquaria at a density of 80 fish per aquarium and subjected to a sex-reversal treatment by immersion application of licorise root extract for 30 days.

Licorise root was provided from Hatay province (Turkey). The aqueous extracts of Licorice root was prepared by boiling 7.5 and $15 \mathrm{~g}$ Licorice root in $250 \mathrm{ml}$ distilled water for $30 \mathrm{~min}$ and then filtering it with a whatman filter paper twice [20,21]. The licorise root extract was incorporated into the aquarium water as follows: 0 (control), 0.25 and $0.5 \mathrm{~g} / \mathrm{L}$ licorice root extract. The prepared solutions were poured in the aquariums. The aquariums were aired strongly to spread the solutions in water. Each of the treatment group was randomly assigned to triplicate groups of fish. The treatment was repeated twice (in the beginning and half way through the experiment) during 30 days [10]. The water of the aquaria was changed entirely every 15 days. The aquaria were controlled temperature $\left(26 \pm 1^{\circ} \mathrm{C}\right)$ and equipped with aeration. The photoperiod was maintained on a 12-h light: 12-h dark schedule. A control group was also included in this experiment. Hatchlings were fed ad-libitum three times a day until satiation. 
The basic food was ornamental fish diet (Aquamaks, Turkey: 28\% protein, $12 \%$ lipid (on wet basis)). After completion of the treatment, they were transferred to larger aquaria. When individuals were 2 months old, the sex of each was determined by external examination, with gonopodium and other morphological characters [22]. In addition, for histological examination of gonads, guppy were fixed in $10 \%$ neutral formalin. After fixing the samples, specimens, excluding head and caudal regions were processed for histology using routine de- hydration and parafin-embedding procedures. Cross-sections of thickness 4-6 $\mathrm{mm}$, were stained with Mayer's haematoxylin and eosin phloxine B solution examined, and microphotography [23]. Growth and survival rate were monitored to determine the growth in each treatment groups during the experiment. Each fish was individually anesthetized with $300 \mathrm{mg} \mathrm{L}^{-1}$ lidocaineHCL $\backslash 1000 \mathrm{mg} \mathrm{L}^{-1} \mathrm{NaHCO}_{3}$ [24], weighed and measured (total length) to the nearest $0.0001 \mathrm{~g}$ and $0.01 \mathrm{~cm}$, respectively. A Chi-square $\left(\chi^{2}\right)$ test was used to determine whether observed sex ratios are different from an expected 1:1. Also, differences in growth were assessed by one-way ANOVA test and Duncan test was used to analyze which dosage groups cause the difference [25].

\section{RESULTS and DISCUSSIONS}

In the present investigation, both 0.25 and $0.5 \mathrm{~g} / \mathrm{L}$ groups of licorise root extract- treated fish exhibited more female number than male number comparing to the control group. The sex ratio in the $P$. reticulata in these groups significantly changed $(\mathrm{p}<0.001$; Table 1$)$ and the highest feminization $(88.35 \%)$ was observed at $0.5 \mathrm{~g} \backslash \mathrm{L}$ licorise root extract group. Also, the sex ratio observed in $0.25 \mathrm{~g} / \mathrm{L}$ groups of licorise root extract- treated fish was 137:70 (female:male); this difference was statistically significant. The sex ratio observed for the $P$. reticulata was nearly the expected ratio of 1:1 (female:male) in control group. (Table, 1). Morphological and histological examination of the gonads in all treatment groups revealed that no intersex fish were identified in guppy. Histological examination of fish treated with licorise root revealed no damage to the testes or ovaries.

Table 1. Effects of treatment with Licorise root extract on sex reversal of the Poecilia reticulata.

\begin{tabular}{cccccc}
\hline & $\begin{array}{c}\text { Dose } \\
(\mathrm{g} / \mathrm{L})\end{array}$ & $\begin{array}{c}\text { Treatment } \\
\text { Duration } \\
(\text { day })\end{array}$ & $\begin{array}{c}\text { Sex Distribution } \\
(\mathrm{n})\end{array}$ & $\begin{array}{c}\text { Sex Ratio } \\
(\%)\end{array}$ & $\chi^{2}$ \\
\hline $\begin{array}{c}\text { Licorise } \\
\text { root extract }\end{array}$ & 0 & 30 & $102: 107$ & $48.80: 51.20$ & - \\
& 0.25 & 30 & $137: 70$ & $66.18: 33.82$ & $12.851^{* * *}$ \\
& 0.5 & 30 & $182: 24$ & $88.35: 11.65$ & $75.105^{* * *}$ \\
\hline$\chi^{2}$ values are for comparisons of sex ratios with the control $(*, \mathrm{P}<0.05 ; * *, \mathrm{P}<0.01 ; * * *, \mathrm{P}<0.001)$.
\end{tabular}

Table 2 shows the survival rate and growth rates in total length and body weight of the $P$. reticulata. Total survival rates and growth rate in all treatments and controls were uniformly high ranging from $85.83 \%$ to $87.08 \%$ and 0.197 to $0.189 \mathrm{~g}$ respectively ( $\mathrm{p}>0.05$ ). This indicates that Licorise root extract has no negative effect on survival and growth rate of $P$. reticulata at the tested concentrations (Table 2). 
Table 2. Effects of treatment with Licorise root extract on survival and growth of the Poecilia reticulata.

\begin{tabular}{ccccc}
\hline & $\begin{array}{c}\text { Dose } \\
(\mathrm{g} / \mathrm{L})\end{array}$ & $\begin{array}{c}\text { Survival Rate } \\
(\%)\end{array}$ & $\begin{array}{c}\text { Total length } \\
(\mathrm{cm})\end{array}$ & $\begin{array}{c}\text { Body weight } \\
(\mathrm{g})\end{array}$ \\
\hline $\begin{array}{c}\text { Licorise root } \\
\text { extract }\end{array}$ & 0 & $87.08 \pm 1.10^{\mathrm{a}}$ & $1.85 \pm 0.06^{\mathrm{a}}$ & $0.197 \pm 0.01^{\mathrm{a}}$ \\
& 12.5 & $86.25 \pm 0.72^{\mathrm{a}}$ & $1.79 \pm 0.08^{\mathrm{a}}$ & $0.192 \pm 0.01^{\mathrm{a}}$ \\
& 25 & $85.83 \pm 0.42^{\mathrm{a}}$ & $1.80 \pm 0.11^{\mathrm{a}}$ & $0.189 \pm 0.01^{\mathrm{a}}$
\end{tabular}

Values (mean \pm S.E. of triplicate) with same superscripts in each column indicate insignificant differences $(\mathrm{P}>0.05)$ (Water temperature $26 \pm 1^{\circ} \mathrm{C}$ ).

To our knowledge, this is the first report regarding the potential of Licorise root extract as a feminization agent in ornamental fish. The $0.5 \mathrm{~g} \backslash \mathrm{L}$ licorise root extract group was the most potent dose in this study, having duration of 30days for feminization. Although the treatment of the newly-born progenies using Licorise root extract significantly increased the percentage of females to $88.35 \%$, we cannot conclude that this potency was caused by an increase of estrogen since we did not measure plasma estrogen levels. The Licorise root extract did not produce $100 \%$ females; a higher dose may have generated better results. Most literature on Licorise treatments in humans [13,26,27] and rats [28,29] endocrine system because it contains isoflavones (phytoestrogens), which are chemicals found in plants that may mimic the effects of estrogen. Licorice may also reduce testosterone levels, which can contribute to hirsutism in women. Therefore, usage of a higher dose may lead to the production of all-female $P$. reticulata population. Most authors have reported similar observation for other fish species, treated with various phytoestogens $[8,9,10,11,30]$. However, the use of of Licorice plant in fish studies was rather limited so far [7]. Also, survival rate of the Licorise -treated $P$. reticulata was similar to that of control group of the experiment. Similarly, survival was high in studies on guppy $P$. reticulata and zebra cichlids $C$. nigrofasciatum [10].

In summary, this study demonstrated that sex differentiation of guppies was successfully diverted toward the female gender with treatment of licorise root extract. The findings of this study indicate the probability of using herbal compounds as an alternative method for production of all-female guppy population. However, further studies will be required to determine the optimum treatment regime for induction of $100 \%$ sex reversal with these chemicals in guppy.

\section{Conflict of Interests}

Authors declare that there is no conflict of interests.

\section{REFERENCES}

[1] Villa-Cruz, V., Davila, J., Viana, M. T., \& Vazquez-Duhalt, R. (2009). Effect of broccoli (Brassica oleracea) and its phytochemical sulforaphane in balanced diets on the detoxification enzymes levels of tilapia (Oreochromis niloticus) exposed to a carcinogenic and mutagenic pollutant. Chemosphere, 74(9), 1145-1151.

[2] Makkar, H. P. S., Francis, G., \& Becker, K. (2007). Bioactivity of phytochemicals in some lesser-known plants and their effects and potential applications in livestock and aquaculture production systems. Animal, 1(9), 1371-1391.

[3] Denev, S. A. (2008). Ecological alternatives of antibiotic growth promoters in the animal husbandry and aquaculture. DSc(Doctoral dissertation, Thesis, Department of Biochemistry Microbiology, Trakia University, Stara Zagora, Bulgaria). 
[4] Dixon, R. A. (2004). Phytoestrogens. Annu. Rev. Plant Biol., 55, 225-261.

[5] Setchell, K. D. (1998). Phytoestrogens: the biochemistry, physiology, and implications for human health of soy isoflavones. The American Journal of Clinical Nutrition, 68(6), 1333S-1346S.

[6] Setchell, K. D. R. (1995). Non-steroidal estrogens of dietary origin: possible roles in health and disease, metabolism and physiological effects. In Proc. Nutr. Soc. NZ (Vol. 20, pp. 121).

[7] Tzchori, I., Degani, G., Elisha, R., Eliyahu, R., Hurvitz, A., Vaya, J., \& Moav, B. (2004). The influence of phytoestrogens and oestradiol-17 $\beta$ on growth and sex determination in the European eel (Anguilla anguilla). Aquaculture research, 35(13), 1213-1219.

[8] Turan, F., \& Akyurt, I. (2005). Effects of red clover extract on growth performance and body composition of African catfish Clarias gariepinus. Fisheries Science, 71(3), 618-620.

[9] Turan, F. (2006). Improvement of growth performance in tilapia (Orepochrimis aureus Linnaeus) by supplementation of red clover Trifolium pratense in diets.

[10] Cek, S., Turan, F., \& Atik, E. (2007). The effects of Gokshura, Tribulus terrestris on sex reversal of guppy, Poecilia reticulata. Pakistan journal of biological sciences: PJBS, 10(5), 718-725.

[11] Chakraborty, S. B., \& Hancz, C. (2011). Application of phytochemicals as immunostimulant, antipathogenic and antistress agents in finfish culture. Reviews in Aquaculture, 3(3), 103-119.

[12] Armanini, D., Fiore, C., Mattarello, M. J., Bielenberg, J., \& Palermo, M. (2002). History of the endocrine effects of licorice. Experimental and clinical endocrinology \& diabetes, 110(06), 257-261.

[13] Armanini, D., Mattarello, M. J., Fiore, C., Bonanni, G., Scaroni, C., Sartorato, P., \& Palermo, M. (2004). Licorice reduces serum testosterone in healthy women. Steroids, 69(11), 763-766.

[14] Davis, E. A., \& Morris, D. J. (1991). Medicinal uses of licorice through the millennia: the good and plenty of it. Molecular and cellular endocrinology, 78(1), 1-6.

[15] Barbieri, R. L., Rein, M. S., Hornstein, M. D., \& Ryan, K. J. (1988). Rat Leydig cell and granulosa cell 17-ketosteroid reductase activity: subcellular localization and substrate specificity. American journal of obstetrics and gynecology, 159(6), 1564-1569.

[16] Takeuchi, T., Nishii, O., Okamura, T., \& Yaginuma, T. (1991). Effect of paeoniflorin, glycyrrhizin and glycyrrhetic acid on ovarian androgen production. The American journal of Chinese medicine, 19(01), 73-78.

[17] Armanini, D., Bonanni, G., \& Palermo, M. (1999). Reduction of serum testosterone in men by licorice. New England Journal of Medicine, 341(15), 1158-1158.

[18] Armanini, D., Bonanni, G., Mattarello, M. J., Fiore, C., Sartorato, P., \& Palermo, M. (2003). Licorice consumption and serum testosterone in healthy man. Experimental and clinical endocrinology \& diabetes, 111(06), 341-343.

[19] Tamaya, T., Sato, S., \& Okada, H. H. (1986). Possible mechanism of steroid action of the plant herb extracts glycyrrhizin, glycyrrhetinic acid, and paeoniflorin: inhibition by plant herb extracts of steroid protein binding in the rabbit. American journal of obstetrics and gynecology, 155(5), 1134-1139.

[20] Joshi, V. S., Parekh, B. B., Joshi, M. J., \& Vaidya, A. B. (2005). Herbal extracts of Tribulus terrestris and Bergenia ligulata inhibit growth of calcium oxalate monohydrate crystals in vitro. Journal of Crystal Growth, 275(1), 1403-1408. 
[21] Gauthaman, K., \& Adaikan, P. G. (2005). Effect of Tribulusterrestris on nicotinamide adenine dinucleotide phosphate-diaphorase activity and androgen receptors in rat brain. Journal of ethnopharmacology, 96(1), 127-132.

[22] Kavumpurath, S., \& Pandian, T. J. (1993). Production of a YY female guppy, Poecilia reticulata, by endocrine sex reversal and progeny testing. Aquaculture, 118(3-4), 183-189.

[23] Çek, Ş., Bromage, N., Randall, C., \& Rana, K. (2001). Oogenesis, hepatosomatic and gonadosomatic indexes, and sex ratio in rosy barb (Puntius conchonius). Turkish journal of fisheries and Aquatic Sciences, 1(2).

[24] Park, I. S., Kim, J. M., Kim, Y. H., \& Kim, D. S. (1988). Influence of lidocaine as an anaesthetic for marine fishes. Journal of fish pathology, 1(2), 123-130.

[25] Norusis, M. J. (1993). SPSS for windows: advanced statistics, release 6.0 (pp. 107-144). Chicago: SPSS inc..

[26] Grant, P., \& Ramasamy, S. (2012). An update on plant derived antiandrogens. International journal of endocrinology and metabolism, 10(2), 497.

[27] Simons, R., Vincken, J. P., Mol, L. A., Bovee, T. F., Luijendijk, T. J., Verbruggen, M. A., \& Gruppen, H. (2011). Agonistic and antagonistic estrogens in licorice root (Glycyrrhiza glabra). Analytical and bioanalytical chemistry, 401(1), 305-313.

[28] Somjen, D., Knoll, E., Vaya, J., Stern, N., \& Tamir, S. (2004). Estrogen-like activity of licorice root constituents: glabridin and glabrene, in vascular tissues in vitro and in vivo. The Journal of steroid biochemistry and molecular biology, 91(3), 147-155.

[29] Simmler, C., Pauli, G. F., \& Chen, S. N. (2013). Phytochemistry and biological properties of glabridin. Fitoterapia, 90, 160-184.

[30] Turan, F., \& Cek, S. (2007). Masculinization of African catfish (Clarias gariepinus) treated with gokshura (Tribulus terrestris). 